Original Article

\title{
Factors that affect the changes in the satisfaction of Japanese physical therapists with their profession over the years
}

\author{
Munetsugu Kota, PhD, RPT 1)*, Hiroyuki Kudo, MS, RPT ${ }^{2)}$, Makoto Takahashi, PhD, RPT 3 ) \\ 1) Hiroshima Cosmopolitan University: 3-2-1 Otsuka-Higashi, Asaminami-ku, Hiroshima City, Hiroshima 731-3166, Japan \\ 2) Hiroshima City Rehabilitation Hospital, Japan \\ 3) Graduate School of Biomedical and Health Sciences, Hiroshima University, Japan
}

\begin{abstract}
Purpose] To analyze changes in the level of satisfaction of new physical therapists with their profession over time and in the factors that affect their satisfaction, focusing on the impact of previous experiences and working conditions. [Participants and Methods] This longitudinal survey study administered a questionnaire to 585 physical therapists who participated in the newcomer orientation at Hiroshima Prefectural Physical Therapy Association from 2017 to 2019 as follows: 210 in 2017, 188 in 2018, and 187 in 2019. The responses to the questions regarding professional satisfaction and the factors that affect it were investigated. The factors identified consisted of the motivation to become a physical therapist, learning in school, clinical internship, working environment, and workplace comfort. A 5-point Likert scale (strongly agree, agree, undecided, disagree, and strongly disagree) was used. [Results] A significant difference was observed in the satisfaction with profession over the 3 year period, and the results of the multiple comparison tests showed a difference between 2018 and 2019. Among the factors identified, positive professional perceptions in clinical internship strongly influenced professional satisfaction over time. [Conclusion] The 1 year longitudinal study revealed a decline in professional satisfaction among the new physical therapists. The characteristic changes in the factors of professional satisfaction were determined from the motivation to become a physical therapist to the clinical internship experience.

Key words: Satisfaction, Physical therapists, Career development
\end{abstract}

(This article was submitted Oct. 20, 2020, and was accepted Dec. 1, 2020)

\section{INTRODUCTION}

Satisfaction with profession is reportedly related to job performance ${ }^{1)}$. Therefore, the job satisfaction level of a physical therapist's experiences during the first year is important to determine the future of their career.

Several studies have reported the career satisfaction of medical professionals ${ }^{2-5}$ ); however, only a few studies exist on professional satisfaction with physical therapists. Stith et al. ${ }^{6)}$ investigated physical therapy students' satisfaction and reported that satisfaction was best explained by factors affecting the interpersonal domain and student gender. In studies on levels of career recognition experienced by physical therapists, studies have reported differences in career success and expectations according to gender $\left.{ }^{7}, 8\right)$, and other studies on levels of career recognition reported a relationship between personality characteristics and career goals ${ }^{9}$. These previous studies on the career recognition of physical therapists revealed that investigations of the impact of past experiences on professional satisfaction were limited. However, past experiences, such as motivation for deciding to become a physical therapist, learning in school, and clinical internship experiences, also influence their professional satisfaction in practice.

In recent years, there has been an oversupply of physical therapists in Japan. The number of physical therapists currently

*Corresponding author. Munetsugu Kota (E-mail: munetsugu@gmail.com)

(C2021 The Society of Physical Therapy Science. Published by IPEC Inc.

(c) (1) $\odot$ This is an open-access article distributed under the terms of the Creative Commons Attribution Non-Commercial No Deriva-

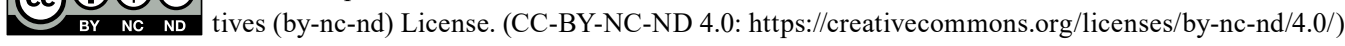


exceeds the number of demands, and by 2040 , the number of supplies is estimated to be approximately 1.5 times greater than the number of demands ${ }^{10}$. An oversupply of professionals such as teachers and physicians has also been reported ${ }^{11,12)}$, and the salary issue and profession quality have been mentioned. According to these reports that a rapid oversupply occurred in recent years, we hypothesize that the satisfaction with physical therapists' profession in Japan may have change over the years.

We targeted new physical therapists with no work experience, who were assumed to be most likely to reflect the effects of changes in the educational environment due to oversupply, and this study aimed to analyze changes in satisfaction with new physical therapists' profession over time and changes in factors affecting satisfaction focusing on the impact of previous experiences such as student life, and present working conditions.

\section{PARTICIPANTS AND METHODS}

In 2018, the Japan Ministry of Health, Labor, and Welfare issued the "Teaching Rules and Guidelines for Physical and Occupational Therapist Training Schools", specifying a clinical clerkship as the recommended format for clinical training. With a view to reflecting these changes in educational content, the research institute was set up from 2017 to 2019 . A total of 585 physical therapists participated in the newcomer orientation at Hiroshima Prefectural Physical Therapy Association from 2017 to 2019: 210 in 2017, 188 in 2018, and 187 in 2019. The response rate was $100 \%, 96 \%$, and 98\%, respectively. Then, after removing responses with missing values, 564 responses (193 in 2017, 188 in 2018, and 183 in 2019) were included in the analysis.

Questionnaires were created specifically for this study. Satisfaction with physical therapists' profession (hereinafter referred to as professional satisfaction) were assessed by question, that is, "I am satisfied with the physical therapy profession" prepared with reference to a previous study ${ }^{3}$. Concerning factors affecting professional satisfaction (hereinafter referred to as affecting factors), several questions were created to address the motivation for becoming physical therapist, learning in school, learning in clinical internship, learning in the working environment, and comfort in the workplace (Table 1). A five-point Likert scale (strongly agree, agree, undecided, disagree, and strongly disagree) was used.

Regarding the statistical analysis, changes in responses to each questionnaire item over 3 years were compared using the Kruskal-Wallis test. Questionnaire items that showed significant differences over a 3 year comparison were subjected to a multiple comparison using the Steel-Dwass test. Relationships between professional satisfaction and affecting factors were analyzed by Spearman's rank-order correlation test. According to Cohen ${ }^{13)}$, the moderate effect size defined that Spearman's rank correlation was $\geq 0.3$ and $<0.5$, and strong effect size defined that Spearman's rank correlation was $\geq 0.5$. A logistic regression analysis was conducted to identify affecting factors that explain professional satisfaction each year. In the logistic regression analysis, questionnaire responses on professional satisfaction and each affecting factor were converted from a 5 scale to a 2 scale of "agree" (strongly agree and agree) or "not agree" (undecided, disagree and strongly disagree). Among the affecting factors, items that were moderately or more significantly correlated with professional satisfaction were adopted as explanatory variables in the logistic regression analysis. The goodness-of-fit of model equations obtained by the logistic regression analysis was analyzed using the Hosmer and Lemeshow goodness-of-fit test, area under the receiver operating characteristic curve (AUC), sensitivity, and specificity. All statistical analyses were performed using R 3.4.0 for Mac, with the significance level set at $5 \%$.

This research was conducted with the approval from the Research Ethics Committee of the Hiroshima Prefectural Physical Therapy Association (approval number 29-0023). All participants were informed of what they were participating in, and only those who agreed to share their information were provided with the questionnaire.

\section{RESULTS}

A significant difference was observed in professional satisfaction over the 3 year comparison, and multiple comparison tests showed a difference between 2018 and 2019 (Table 2). The percentage of respondents that "strongly agree" and "agree" added together was $76.1 \%$ in 2018 and $65.1 \%$ in 2019 . Significant differences in affecting factors were observed over the 3 year comparison in items of "Learning in clinical internship" question 1 (hereinafter, this is called "LC1"), "Comfort in the workplace" question 2 (hereinafter, this is called "CW2"), and "Comfort in the workplace" question 2 (hereinafter, this is called "CW4"). In LC1 items, multiple comparison tests showed a significant difference between 2018 and 2019, and the percentage of respondents who "strongly agree" and "agree" combined was 71.9\% in 2018 and 59.0\% in 2019. In CW2 item, multiple comparison tests showed a difference between 2018 and 2019, and the percentage of respondents who "strongly agree" and "agree" combined was $44.2 \%$ in 2018 and 32.2\% in 2019. In CW4 item, multiple comparison tests showed a difference between 2017 and 2019, and the percentage of respondents who "strongly agree" and "agree" combined was 56.9\% in 2017 and $65.0 \%$ in 2019 (Table 2).

Relationships between professional satisfaction and affecting factors are indicated in Table 3.

In the logistic regression analysis, items adopted as affecting factors to explain professional satisfaction in 2017 were "Motivation for becoming physical therapist" question 3 (hereinafter, this is called "MP3") and "Learning in the working environment" question 1 (hereinafter, this is called "LW1"), in 2018 were LW1, and in 2019 were LC1, LW1, and "Learning in the working environment" question 3 (hereinafter, this is called "LW3"). The p-value of the Hosmer and Lemeshow 
Table 1. Question items about the satisfaction with profession and affecting factors

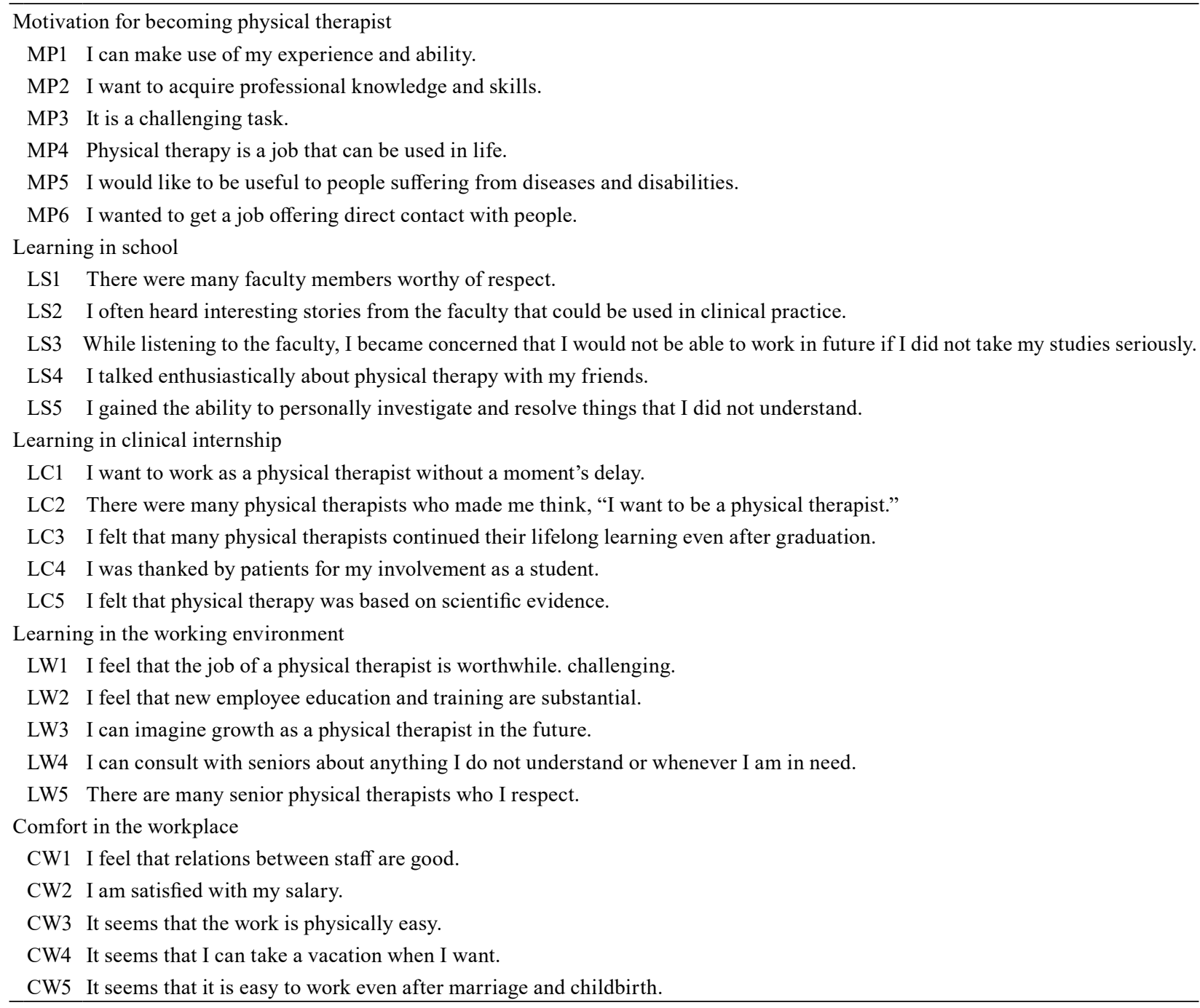

goodness-of-fit test in each year's logistic model was 0.874 in 2017, 0.981 in 2018, and 0.998 in 2019. AUC in each year's logistic model was 0.845 in 2017, 0.815 in 2018, and 0.871 in 2019 (Table 4).

\section{DISCUSSION}

The LC1 question, which declined between 2108 and 2019 significantly, was "I want to work as a physical therapist without a moment's delay", which was significantly correlated with professional satisfaction, with the correlation becoming stronger each year. LC1 was also adopted as an explanatory variable for the logistic regression analysis of professional satisfaction in 2019 (Table 4), inferring that LC1 was strongly associated with professional satisfaction among affecting factors investigated in the current study. Clinical internships, taking place during the student days, are an opportunity to experience the work of a physical therapist for the first time, and whether this professional experience is perceived positively or not was found to be a factor that explains professional satisfaction after becoming a physical therapist.

Conversely, LW1, which asked about positive perceptions of physiotherapy work the time of survey response, was adopted a factor that explains professional satisfaction in all years (Table 4). In Japan, clinical internship for physical therapy students had consisted of an assigned-patient training format in which students were assigned a few patients to evaluate and treat under supervision. However, this training format has been viewed as problematic due to the need for assignments of certain patients. Another problem observed that students spend many hours writing case reports regarding their assigned patients or performing other tasks after finishing their clinical training time. To resolve these issues in the clinical training of therapists, the Japan Ministry of Health, Labor, and Welfare issued the "Teaching Rules and Guidelines for Physical and Occupational Therapist Training Schools" in October 2018, specifying a clinical clerkship as the recommended format for clinical training. Clinical clerkship refers to students' proactive participation in the clinical care within a clinical team comprising students and supervisors ${ }^{14)}$. Due to increased real practical experience based on these changes in clinical internship 
Table 2. Annual changes in survey responses

\begin{tabular}{|c|c|c|c|c|c|c|c|c|c|c|c|c|c|c|c|c|c|}
\hline & \multicolumn{5}{|c|}{$2017(n=193)$} & \multicolumn{5}{|c|}{$2018(n=188)$} & \multicolumn{5}{|c|}{$2019(n=183)$} & \multirow[t]{3}{*}{$\mathrm{p}$} & \multirow{3}{*}{$\begin{array}{c}\text { Multiple } \\
\text { comparison }\end{array}$} \\
\hline & SD & $\mathrm{D}$ & $\mathrm{U}$ & A & SA & SD & $\mathrm{D}$ & $\mathrm{U}$ & A & SA & SD & $\mathrm{D}$ & $\mathrm{U}$ & A & SA & & \\
\hline & \multicolumn{5}{|c|}{$\%$} & \multicolumn{5}{|c|}{$\%$} & \multicolumn{5}{|c|}{$\%$} & & \\
\hline \multicolumn{18}{|c|}{ Satisfaction with physical therapy as a job } \\
\hline & 2.1 & 2.6 & 20.7 & 58.0 & 16.6 & 1.6 & 3.2 & 19.1 & 53.2 & 22.9 & 1.1 & 4.9 & 29.0 & 52.5 & 12.6 & 0.010 & $2018-2019$ \\
\hline \multicolumn{18}{|c|}{ Motivation for becoming physical therapist } \\
\hline MP1 & 9.8 & 18.7 & 28.5 & 36.8 & 6.2 & 10.6 & 15.4 & 27.7 & 35.6 & 10.6 & 13.1 & 16.9 & 29.0 & 34.4 & 6.6 & 0.403 & \\
\hline MP2 & 7.8 & 11.4 & 19.7 & 40.4 & 20.7 & 3.7 & 6.9 & 20.7 & 43.1 & 25.5 & 6.6 & 9.8 & 18.6 & 48.1 & 16.9 & 0.099 & \\
\hline MP3 & 2.6 & 2.6 & 10.9 & 46.1 & 37.8 & 1.1 & 2.7 & 8.0 & 46.8 & 41.5 & 2.7 & 2.7 & 10.4 & 50.3 & 33.9 & 0.237 & \\
\hline MP4 & 5.7 & 10.9 & 27.5 & 36.8 & 19.2 & 4.8 & 9.0 & 27.1 & 37.2 & 21.8 & 8.2 & 13.1 & 28.4 & 33.9 & 16.4 & 0.109 & \\
\hline MP5 & 2.1 & 1.0 & 11.9 & 46.1 & 38.9 & 1.6 & 1.6 & 9.6 & 51.1 & 36.2 & 1.6 & 2.2 & 8.2 & 50.8 & 37.2 & 0.972 & \\
\hline MP6 & 5.2 & 9.3 & 22.8 & 35.8 & 26.9 & 3.7 & 4.8 & 22.9 & 37.8 & 30.9 & 5.5 & 4.9 & 27.9 & 39.9 & 21.9 & 0.141 & \\
\hline \multicolumn{18}{|c|}{ Learning in school } \\
\hline LS1 & 5.2 & 8.3 & 15.0 & 42.5 & 29.0 & 4.3 & 9.0 & 13.8 & 44.7 & 28.2 & 1.6 & 11.5 & 14.2 & 47.0 & 25.7 & 0.961 & \\
\hline LS2 & 3.1 & 8.8 & 15.0 & 48.7 & 24.4 & 1.6 & 9.0 & 19.7 & 45.7 & 23.9 & 2.2 & 10.9 & 21.3 & 42.1 & 23.5 & 0.596 & \\
\hline LS3 & 2.6 & 5.2 & 10.9 & 46.1 & 35.2 & 3.2 & 5.9 & 12.8 & 44.7 & 33.5 & 0.5 & 7.7 & 17.5 & 41.0 & 33.3 & 0.611 & \\
\hline LS4 & 3.1 & 17.1 & 28.5 & 38.3 & 13.0 & 4.8 & 12.8 & 29.8 & 39.4 & 13.3 & 5.5 & 18.0 & 31.1 & 32.2 & 13.1 & 0.369 & \\
\hline LS5 & 0.5 & 4.7 & 26.9 & 53.4 & 14.5 & 0.5 & 5.3 & 22.9 & 59.6 & 11.7 & 0.0 & 3.3 & 30.6 & 54.1 & 12.0 & 0.822 & \\
\hline \multicolumn{18}{|c|}{ Learning in clinical internship } \\
\hline $\mathrm{LC} 1$ & 4.1 & 12.4 & 20.7 & 33.2 & 29.5 & 2.1 & 9.0 & 17.0 & 41.0 & 30.9 & 2.2 & 15.8 & 23.0 & 37.7 & 21.3 & 0.023 & 2018-2019 \\
\hline $\mathrm{LC} 2$ & 2.1 & 8.3 & 13.5 & 43.0 & 33.2 & 0.0 & 6.4 & 14.9 & 41.0 & 37.8 & 2.2 & 5.5 & 13.1 & 45.4 & 33.9 & 0.552 & \\
\hline LC3 & 2.1 & 4.1 & 10.9 & 33.2 & 49.7 & 0.0 & 1.1 & 9.6 & 36.2 & 53.2 & 0.5 & 2.7 & 10.4 & 39.3 & 47.0 & 0.341 & \\
\hline LC4 & 0.0 & 2.6 & 10.9 & 56.5 & 30.1 & 1.1 & 1.6 & 6.9 & 48.9 & 41.5 & 0.0 & 2.7 & 12.6 & 46.4 & 38.3 & 0.072 & \\
\hline LC5 & 0.5 & 8.8 & 29.0 & 44.6 & 17.1 & 1.1 & 4.3 & 26.6 & 53.2 & 14.9 & 2.2 & 5.5 & 30.1 & 45.9 & 16.4 & 0.627 & \\
\hline \multicolumn{18}{|c|}{ Learning in the working environment } \\
\hline LW1 & 1.6 & 3.1 & 18.7 & 50.3 & 26.4 & 0.0 & 2.7 & 18.6 & 50.5 & 28.2 & 2.2 & 2.2 & 19.1 & 48.6 & 27.9 & 0.831 & \\
\hline LW2 & 5.7 & 6.2 & 19.7 & 37.8 & 30.6 & 3.2 & 9.6 & 17.6 & 38.3 & 31.4 & 3.8 & 7.7 & 27.3 & 27.9 & 33.3 & 0.858 & \\
\hline LW3 & 6.7 & 13.5 & 36.3 & 34.2 & 9.3 & 5.3 & 13.8 & 35.6 & 38.3 & 6.9 & 7.7 & 12.0 & 36.6 & 31.1 & 12.6 & 0.958 & \\
\hline LW4 & 2.1 & 4.7 & 6.7 & 40.9 & 45.6 & 2.7 & 2.7 & 9.6 & 43.6 & 41.5 & 1.1 & 6.0 & 7.1 & 42.6 & 43.2 & 0.749 & \\
\hline LW5 & 3.1 & 3.1 & 10.4 & 38.9 & 44.6 & 2.7 & 3.7 & 12.8 & 38.8 & 42.0 & 2.2 & 2.2 & 14.2 & 47.0 & 34.4 & 0.258 & \\
\hline \multicolumn{18}{|c|}{ Comfort in the workplace } \\
\hline CW1 & 1.0 & 3.6 & 8.3 & 40.4 & 46.6 & 1.6 & 2.7 & 6.9 & 39.4 & 49.5 & 1.1 & 4.9 & 9.3 & 33.9 & 50.8 & 0.818 & \\
\hline CW2 & 13.0 & 17.6 & 30.1 & 29.0 & 10.4 & 10.6 & 14.4 & 30.9 & 31.4 & 12.8 & 18.6 & 18.0 & 31.1 & 24.0 & 8.2 & 0.016 & 2018-2019 \\
\hline CW3 & 11.9 & 39.9 & 36.3 & 9.3 & 2.6 & 11.7 & 43.1 & 29.8 & 12.2 & 3.2 & 12.6 & 44.3 & 30.6 & 8.7 & 3.8 & 0.783 & \\
\hline CW4 & 8.3 & 13.5 & 23.3 & 37.3 & 17.6 & 4.8 & 13.3 & 25.0 & 31.9 & 25.0 & 4.9 & 8.7 & 21.3 & 39.3 & 25.7 & 0.047 & 2017-2019 \\
\hline CW5 & 5.7 & 6.2 & 20.7 & 40.4 & 26.9 & 2.7 & 8.0 & 20.2 & 37.8 & 31.4 & 3.8 & 3.8 & 19.7 & 43.7 & 29.0 & 0.532 & \\
\hline
\end{tabular}

SA: Strongly agree; A: Agree; U: Undecided; D: Disagree; SD: Strongly disagree.

education, the association between perceptions of the physical therapist's work felt in clinical internship and professional satisfaction with profession after becoming a physical therapist became stronger.

In 2017, MP3 was adopted as an explanatory factor for professional satisfaction (Table 4), and the positive image, a stable job, at the time of their occupational choice had been still affected after becoming a physical therapist. It is interesting to note that over years, correlations between not only MP3 but also other motivational items on becoming a physical therapist and professional satisfaction tended to be no longer found (Table 3), and in 2019, clear career design (LW3) at the time of questionnaire response had been found as an explanatory factor of professional satisfaction instead (Table 4). These results suggest a discrepancy between the image of a physical therapist held at the career choice stage and after learning and experiencing physical therapy in practice. One of the reasons for this discrepancy is that an oversupply of physical therapists ${ }^{10)}$ may have led to an increased number of students choosing a profession without fully understanding the work of a physical therapist.

CW2, a questionnaire on salary satisfaction, declined in 2019, showing to be moderately correlated with professional satisfaction in 2019. However, it was not adopted as an explanatory factor in the logistic regression analysis, revealing that although it was associated with professional satisfaction, it was relatively more strongly associated with career development than that with salary. These results support that of a previous study investigating the professional satisfaction for nurses, physical therapists, and occupational therapists in elderly care organizations, and this previous study indicated that 
Table 3. Relationships between satisfaction with the profession and affecting factors

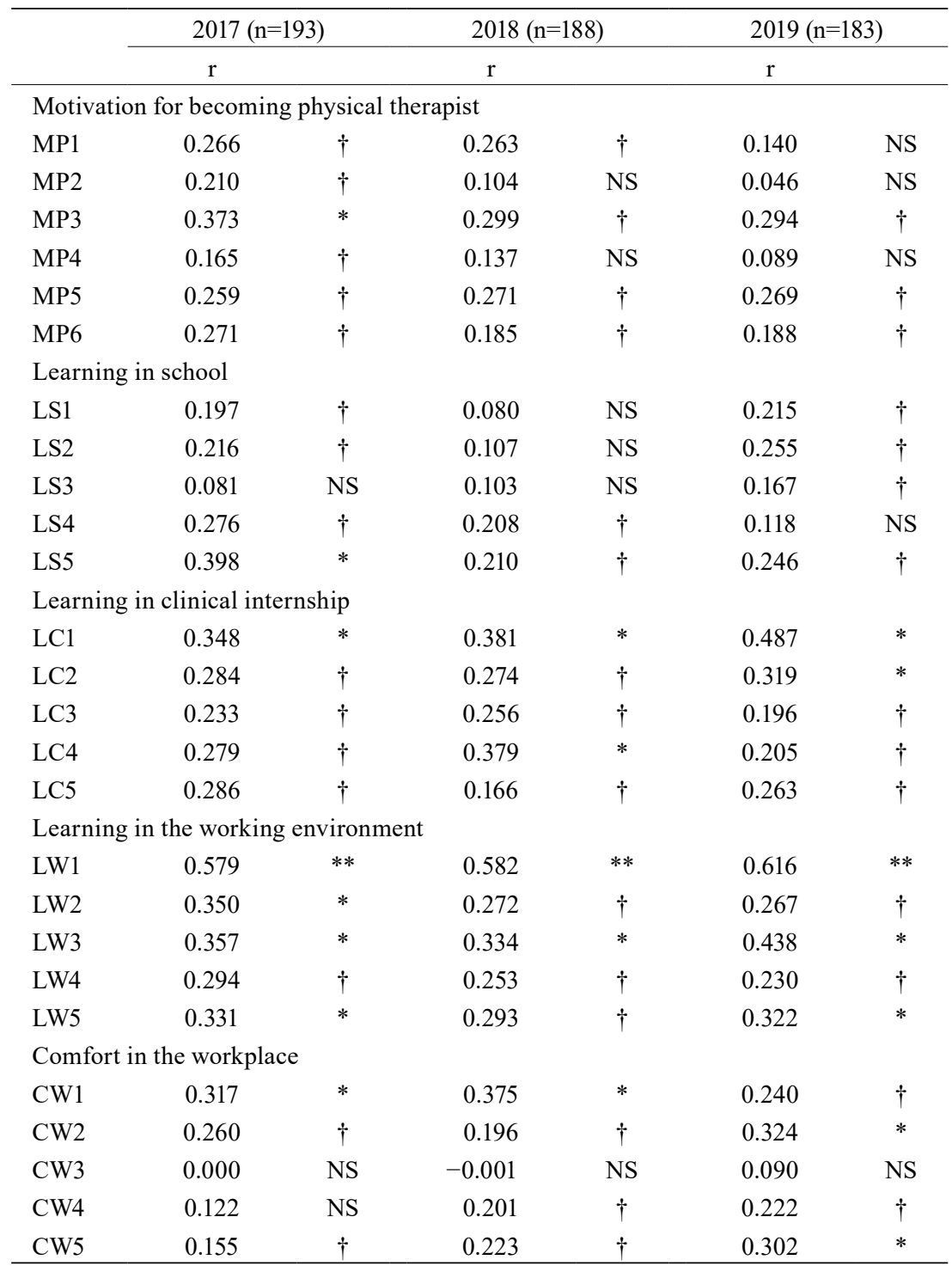

Spearman's correlation coefficient test.

NS: $\mathrm{p} \geq 0.05$.

$\dagger: \mathrm{r}<0.3, \mathrm{p}<0.05$.

$*: \mathrm{r} \geq 0.3, \mathrm{p}<0.05$.

$* *: \mathrm{r} \geq 0.5, \mathrm{p}<0.05$.

well-functioning work, stimulating work task, and good leadership had a stronger effect on the satisfaction than economic reward ${ }^{15}$. However, if the oversupply of physical therapists continues and the environment of economic reward deteriorates further, its negative impact on professional satisfaction may become stronger and therefore should continue to be investigated in the future.

CW4 improved in 2019 as compared to 2017; however, it was not an explanatory factor for professional satisfaction in all years. This result was inferred to be influenced by the enactment of the 2018 work style reform law by the Japanese Parliament. Since this study participants were new physical therapists, most of them came from single households and can be inferred that the impact of the work style reform, such as ease of taking a vacation, on professional satisfaction was insignificant.

A limitation of this study is that we have not been able to investigate the forms of clinical internship that have been found to have a significant impact on the satisfaction with profession of new physical therapists (clinical clerkship or conventional training). Also, although results of this study cannot extend the temporal trend of professional satisfaction among new physical therapists in Japan due to the relatively short period of 3 years and the limited area of Hiroshima Prefecture, significant professional satisfaction and explanatory factors have changed over time. Therefore, the impact of the oversupply of physical therapists and revisions to the physical therapist educational system should be continuously investigated. 
Table 4. Analysis of factors affecting explaining satisfaction with the profession each year

\begin{tabular}{|c|c|c|c|c|c|c|c|c|c|}
\hline & \multicolumn{3}{|c|}{$2017(n=193)$} & \multicolumn{3}{|c|}{$2018(\mathrm{n}=188)$} & \multicolumn{3}{|c|}{$2019(n=183)$} \\
\hline & Adj. OR & $(95 \% \mathrm{CI})$ & $\mathrm{p}$ & Adj. OR & $(95 \% \mathrm{CI})$ & $\mathrm{p}$ & Adj. OR & $(95 \% \mathrm{CI})$ & $\mathrm{p}$ \\
\hline \multicolumn{10}{|c|}{ Motivation for becoming a physical therapist } \\
\hline MP3 & 4.90 & $(1.78,13.49)$ & 0.002 & & & & & & \\
\hline \multicolumn{10}{|c|}{ Learning in school } \\
\hline LS5 & 2.03 & $(0.87,4.72)$ & 0.101 & & & & & & \\
\hline \multicolumn{10}{|c|}{ Learning in the clinical internship } \\
\hline $\mathrm{LC} 1$ & 1.92 & $(0.81,4.52)$ & 0.142 & 1.08 & $(0.41,2.87)$ & 0.876 & 5.27 & $(2.22,12.52)$ & $<0.001$ \\
\hline LC2 & & & & & & & 1.73 & $(0.65,4.62)$ & 0.275 \\
\hline $\mathrm{LC} 4$ & & & & 0.90 & $(0.24,3.38)$ & 0.872 & & & \\
\hline \multicolumn{10}{|c|}{ Learning in the working environment } \\
\hline LW1 & 5.07 & $(1.91,13.45)$ & 0.001 & 13.01 & $(4.91,34.48)$ & $<0.001$ & 4.58 & $(1.74,12.04)$ & 0.002 \\
\hline LW2 & 1.16 & $(0.45,3.01)$ & 0.762 & & & & & & \\
\hline LW3 & 1.40 & $(0.54,3.63)$ & 0.487 & 2.15 & $(0.86,5.34)$ & 0.096 & 3.87 & $(1.54,9.76)$ & 0.003 \\
\hline LW5 & 1.13 & $(0.36,3.57)$ & 0.840 & & & & 0.97 & $(0.36,2.62)$ & 0.951 \\
\hline \multicolumn{10}{|c|}{ Comfort in the workplace } \\
\hline CW1 & 1.85 & $(0.59,5.8)$ & 0.292 & 2.64 & $(0.8,8.73)$ & 0.114 & & & \\
\hline CW2 & & & & & & & 1.83 & $(0.71,4.73)$ & 0.207 \\
\hline CW5 & & & & & & & 1.91 & $(0.74,4.89)$ & 0.177 \\
\hline \multicolumn{10}{|c|}{ Fit of the logistic model } \\
\hline HL test & & 0.874 & & & 0.981 & & & 0.998 & \\
\hline AUC & & 0.845 & & & 0.815 & & & 0.871 & \\
\hline
\end{tabular}

HL test: Hosmer and Lemeshow goodness-of-fit test (p-value).

AUC: Area under the receiver operating characteristic curve.

\section{Conflict of interest}

The authors declare no conflicts of interest associated with this manuscript.

\section{REFERENCES}

1) Judge TA, Thoresen CJ, Bono JE, et al.: The job satisfaction-job performance relationship: a qualitative and quantitative review. Psychol Bull, 2001, 127: 376-407. [Medline] [CrossRef]

2) Carr PL, Ash AS, Friedman RH, et al.: Relation of family responsibilities and gender to the productivity and career satisfaction of medical faculty. Ann Intern Med, 1998, 129: 532-538. [Medline] [CrossRef]

3) Frank E, McMurray JE, Linzer M, et al. Society of General Internal Medicine Career Satisfaction Study Group: Career satisfaction of US women physicians: results from the Women Physicians' Health Study. Arch Intern Med, 1999, 159: 1417-1426. [Medline] [CrossRef]

4) Leigh JP, Kravitz RL, Schembri M, et al.: Physician career satisfaction across specialties. Arch Intern Med, 2002, 162: 1577-1584. [Medline] [CrossRef]

5) McGlynn K, Griffin MQ, Donahue M, et al.: Registered nurse job satisfaction and satisfaction with the professional practice model. J Nurs Manag, 2012, 20: 260-265. [Medline] [CrossRef]

6) Stith JS, Butterfield WH, Strube MJ, et al.: Personal, interpersonal, and organizational influences on student satisfaction with clinical education. Phys Ther, 1998, 78: 635-645. [Medline] [CrossRef]

7) Rozier CK, Raymond MJ, Goldstein MS, et al.: Gender and physical therapy career success factors. Phys Ther, 1998, 78: 690-704. [Medline] [CrossRef]

8) Johanson MA: Sex differences in career expectations of physical therapist students. Phys Ther, 2007, 87: 1199-1211. [Medline] [CrossRef]

9) Jensen GM, Gwyer J, Shepard KF: Expert practice in physical therapy. Phys Ther, 2000, 80: 28-43, discussion 44-52. [Medline] [CrossRef]

10) Ministry of Health, Labor and Welfare: Supply and demand estimates for physical and occupational therapists (in Japanese). https://www.mhlw.go.jp/content/10801000/000499144.pdf (Accessed Oct. 16, 2020)

11) Grumbach K, Coffman JM, Young JQ, et al.: Physician supply and medical education in California. A comparison with national trends. West J Med, 1998, 168: 412-421. [Medline]

12) Ritchie G: Quantifying the effects of teacher movements between schools in New Zealand: to schools that hath, shall be given. J Educ Policy, 2004, 19: 57-79. [CrossRef]

13) Cohen J: A power primer. Psychol Bull, 1992, 112: 155-159. [Medline] [CrossRef]

14) Odo N, Ohtsuka K, Suzuki Y, et al.: Effects of clinical clerkship in education for physical and occupational therapy students: a multifaceted examination using objective indices. Fujita Med J, 2019, Advanced Publication by J-STAGE: DOI https://doi.org/10.20407/fmj.2019-024.

15) Öhman A, Keisu BI, Enberg B: Team social cohesion, professionalism, and patient-centeredness: gendered care work, with special reference to elderly care - a mixed methods study. BMC Health Serv Res, 2017, 17: 381. [Medline] [CrossRef] 